\title{
The Influence of Postnatal Psychiatric Disorder on Child Development
}

\author{
Is Maternal Preoccupation One of the Key Underlying Processes?
}

\author{
Alan Stein $^{a}$ Annukka Lehtonen ${ }^{a}$ Allison G. Harvey ${ }^{b}$ Rosie Nicol-Harper ${ }^{a}$ \\ Michelle Craske ${ }^{c}$ \\ ${ }^{a}$ Department of Psychiatry, University of Oxford, Oxford, UK; ${ }^{b}$ Department of Psychology, University of California, \\ Berkeley, Calif., and 'Department of Psychology, University of California, Los Angeles, Calif., USA
}

\section{Key Words}

Intergenerational transmission - Preoccupation • Worry •

Rumination $\cdot$ Mother-child interaction $\cdot$ Postnatal

psychiatric disorder

\begin{abstract}
There is considerable evidence that maternal postnatal psychiatric disorder has an adverse influence on infant development. In attempting to examine the pathways of intergenerational transmission, most research has concentrated on genetic factors or on maternal behaviours during motherchild interaction and attachment. However, researchers have largely ignored the possible role of maternal cognition underlying behaviour, especially the thought and attentional processes involved in psychiatric disorders. This paper argues that a particular form of maternal cognition, namely 'preoccupation', is one key, but under-recognised, mechanism in the transmission of psychiatric disturbance. We propose that preoccupation interferes with specific aspects of mental functioning, especially attention and responsivity to the environment. This impairs the mother's parenting capacities and adversely affects mother-child interaction and child development.

Copyright $\odot 2008$ S. Karger AG, Basel
\end{abstract}

\section{Introduction}

There is good evidence that parental psychiatric disorder increases the risk of a disturbance in child development [e.g. 1]. There has been particular interest in the impact on the infant of maternal psychiatric disorder occurring during the year following childbirth, as it has been argued that maternal disturbance during key stages of development is particularly likely to have an adverse effect. Indeed, a large body of research shows that maternal psychiatric disorder at this time significantly raises the risk of adverse infant outcome [2]. Much of the research in this area is derived from studies of postnatal depression [3-7], and to some extent from eating disorders [8-11] and anxiety [12]. Furthermore, disturbances in the children may persist well after remission of the parental disorder $[7,13]$.

These findings highlight the need for understanding the mechanisms by which parental disorder influences child development. Considerable progress has been made in identifying mechanisms in a number of domains, including behavioural, attachment [14-16] and genetic [17]. However, maternal cognitions, which are likely to be an important factor underlying maternal behaviours such as sensitivity, have been largely ignored. In particular, little attention has been paid to the effect of the recurrent negative thought processes and the resultant attentional distur-

Professor Alan Stein

University of Oxford, Department of Psychiatry

Warneford Hospital

Oxford OX3 7JX (UK)

Tel. +44 1865223 911, Fax +44 1865226 384, E-Mail alan.stein@psych.ox.ac.uk 
bances that are core features of many psychiatric disorders. In the following, we present the rationale for the hypothesis that particular cognitive processes, characteristic of a number of common psychiatric disorders, underlie the maternal behaviours that are involved in the transmission of disturbance. We have termed these cognitive processes 'preoccupation'. The goal of this paper is to underscore the importance of testing whether preoccupation is one of the contributing factors to an increased risk of adverse effects on child development amongst children of mothers with postnatal psychiatric disorders. There are, of course, several other factors affecting child outcome and maternal insensitivity, such as the already mentioned attachment relationship between the mother and the child [18], the mother's attachment status [14], as well as the mother's selfesteem [19] or empathy [20, 21]. We will not discuss these in detail, as the purpose of this paper is not to provide a comprehensive review, but instead to consider an issue that has thus far received little attention. The suggestion in this paper is that maternal cognitive processes are potentially one of a number of important mechanisms underlying the relationship between postnatal depression and anxiety and child development. We do not propose to review the literature on other mechanisms, as much of it has been well documented.

We use the term preoccupation in the sense that it is defined in the Oxford English Dictionary [22]. Thus, we define preoccupation as a state of narrowed or self-focused attention in which one's mind is dominated by recurrent negative intrusive thoughts that are difficult to control, difficult to dismiss and recur even if dismissed. We hypothesise that because preoccupation interferes with mental functioning, especially attention and, consequently, responsiveness to the child, it has the potential to interfere with responsive parenting and ultimately child development. That is, preoccupation is proposed to be important in mediating the impact of postnatal psychiatric disorders on child development.

We recognise at the outset that the term preoccupation is used in two other contexts as well. Winnicott [23] originally described a process, which he called primary maternal preoccupation, as an essentially normal phenomenon in which parents are focused on their infant around the time of birth and the early months of an infant's life. Subsequently, Leckman et al. [24] provided empirical data on this early parental preoccupation, which is seen as serving a biologically protective function. The adult attachment literature also uses the term preoccupation. In particular, the adult attachment interview categorises individuals as 'preoccupied', describing them as: 'Not coherent, preoccu- pied with or by past attachment relationships/experiences, speakers appear angry, passive or fearful. Sentences often long, grammatically entangled or filled with vague usages...' [25]. These terms are distinguished from the preoccupation defined in this paper, which is negative in nature, strongly associated with psychiatric disorder and which involves a narrowed or self-focused attention, in which one's mind is dominated by recurrent negative intrusive thoughts that are difficult to control, difficult to dismiss and recur even if dismissed. We justify using the term preoccupation as this encompasses the dictionary definition, and therefore we believe it would be inappropriate to substitute the term with another.

\section{Psychiatric Disorder in the Postnatal Period}

Maternal psychiatric disorder in the postnatal period is not uncommon. Postnatal depression is the most common postnatal disorder with a prevalence of around $10 \%$ [26], and has also been given the most attention in research. Anxiety and eating disorders have not received as much consideration, but are assumed to be common postnatally because of their overall prevalence among women of child-bearing age. In epidemiological research that has recruited subjects from across the population as a whole, generalised anxiety disorder (GAD) has a current prevalence between 1.5 and $3 \%$, and a prevalence in the past year between 3 and 5\% [27, 28]. Like other anxiety disorders, it has a chronic course. GAD is twice as common in women as in men [28], typically developing during the early child-bearing years of the late teens to the late 20s [29]. Recently, two studies [30, 31] have suggested that anxiety in the postpartum period (GAD and other anxiety disorders) is more prevalent than previously thought, and thus this is an area of growing interest. Epidemiological studies on the prevalence of eating disorders in the postpartum period have not been conducted, but estimates indicate that at least $2 \%$ of women of child-bearing age suffer from bulimia nervosa or anorexia nervosa, and this figure increases to $4 \%$ when atypical eating disorders are included [32].

\section{Recurrent Negative Thought and Preoccupation in Psychiatric Disorders}

Although sometimes referred to as worry and sometimes as rumination, recurrent negative thoughts appear to be characteristic across a broad range of psychiatric 
disorders (for a review, see Harvey et al. [33]). Worry is considered to be the core component of GAD, and has been defined as 'a chain of thoughts and images, negatively affect-laden and relatively uncontrollable' [34]. Rumination is characteristic of depression [35], and has been defined as thoughts and behaviours that repetitively focus an individual's attention on his or her negative feelings, and the nature and implications of these feelings (including the causes, meanings and consequences of the feelings) [36]. In the context of eating disorders, these two terms have been used interchangeably to describe the type of thoughts involved [37].

We are using the term 'preoccupation' to refer to the core process of recurrent negative thinking that is characteristic across the psychiatric disorders common in the postpartum period, as discussed above. Although recurrent negative thinking is referred to as rumination in the depression literature and as worry in the GAD literature, these two terms are often used interchangeably in most literatures pertaining to other psychiatric disorders. Furthermore, the notion that worry and rumination are really independent phenomena that would justify different terminology has been challenged [38-41]. Thus, it is possible that worry and rumination reflect the same underlying processes [33]. It is also important to note that as depression and anxiety are highly comorbid disorders, it would make sense that the cognitive processes involved are overlapping to a degree.

Although we argue that the cognitive process of recurrent negative thinking is the same across disorders and therefore discuss preoccupation independently of the specific psychiatric disorder in question, it is important to highlight that the content of recurrent negative thinking will be very different for the different disorders and will reflect the current concerns inherent to each disorder $[33,42]$. Recurrent negative thinking can also have both an internal and an external focus. For example, there is evidence that people who are depressed experience recurrent thoughts about their depressive feelings and symptoms, their personal inadequacies and their perceived failures [32] - all thoughts with an internal focus. In contrast, the core feature of GAD is referred to as worry, which includes negative thinking about perceived threats [43-45]. Bulimia nervosa is characterised by preoccupation with eating, body shape and weight $[46,47]$.

Although preoccupation can be considered a core characteristic of several psychiatric disorders, it is not in itself a symptom and therefore is not directly manifest in the symptomatology of the disorders. As a cognitive process that can vary in content, it does not lead exclusively to a specific type of behaviour that would coincide with the conventional symptoms assessed by psychiatric interviews or questionnaires. Instead, it needs to be measured with different questionnaires as well as experimentally. Questionnaires relevant to our concept of preoccupation mainly come from the research traditions studying rumination and worry. These include for example the ruminative response style (the Response Styles Questionnaire [48]), levels of self-focus of attention (the Self-Focus Sentence Completion Task [49]), quality of thoughts (the Global Rumination Scale [50]) or worry (the Penn State Worry Questionnaire [51]). Experimental investigations have measured relevant constructs by, for example, inducing worry or rumination and then comparing the performance of participants who did and participants who did not undergo the induction task. The outcome tasks vary from study to study, including proofreading and reading comprehension [52], or selecting words from a word grid [53]. These studies have found that performance is poorer for participants subjected to the induction task. Thus, the effects of preoccupation as a cognitive process emerge in different ways in different tasks.

\section{Impact of Preoccupation}

There is a large body of work in relation to depression, anxiety and to some extent eating disorders suggesting that negative recurrent thinking, the process that we call preoccupation, has profound effects on a person's capacity to attend to and to respond to the outside world. In the section that follows we review this evidence, before moving on to discuss the relevance of preoccupation for child development.

\section{Attention}

Central to the argument herein is the notion that the recurrent negative thoughts characteristic of preoccupation invariably lead to a narrowed focus of attention. Generally, attentional resources are preferentially allocated to stimuli that have personal relevance, and, in psychiatric disorders, this relevance is affected by the cognitions typical of the disorder. For example, in depression the focus of attention is predominately internal or selffocused $[54,55]$. In anxiety, the attentional focus can be both external, involving scanning the external environment for threat $[56,57]$, and internal, scanning the body for threat [58] and monitoring the self to see how one appears to others [59]. Similarly, both external and internal attentional focus have been implicated in eating disor- 
ders. Relative to controls, individuals with bulimia nervosa selectively attend to weight, shape and eating stimuli [60-67], indicating selective attention to preoccupation-relevant external cues. They also selectively attend to internal cues such as thoughts of worthlessness in relation to body shape and weight [64]. Indeed, it is well established that a narrowed focus of attention toward disorder-congruent stimuli is characteristic of a wide range of psychiatric disorders [33].

Consequently, in the presence of multiple competing stimuli, attention is allocated more to personally relevant stimuli and less to personally irrelevant stimuli. The relevance of stimuli, as mentioned above, is influenced by the disorder in question. Central to our argument is the conceptualisation of Kahneman [65] that attentional resources have limited capacity. Thus, the allocation of attentional resources to personally relevant stimuli as a result of preoccupation impairs the processing of other stimuli in the environment.

This is experimentally demonstrated in cognitive interference paradigms such as the dichotic listening task and the modified Stroop task. In the dichotic listening task, participants are required to verbally repeat ('shadow') non-disorder-relevant information being played to one ear through a pair of headphones, while disorder-relevant and non-disorder-relevant words are presented to the other ear. Attentional bias is indexed by disruptions to the shadowing task when a disorder-congruent word is played in the unattended channel, compared to when a non-threat word is played in the unattended channel. In the modified Stroop paradigm, individuals are shown threat-related words and control words printed in different ink colours. The task is to name the ink colour of the word. Significant delays in colour naming are thought to measure disproportionate allocation of attentional resources to the word stimuli.

Using the dichotic listening task anxious individuals exhibit more disruptions of their shadowing task when threat words are presented to the non-shadow ear [e.g. 66, 67]. In the Stroop task, individuals with an anxiety disorder exhibit a significant delay in naming colours of threat-related words [e.g. 67, 68]. These effects extend to subliminal presentations [e.g. 69].

People diagnosed with depression demonstrate increased emotional Stroop interference for depression-related and negatively valenced words [e.g. 70], although there have been some non-replications [e.g. 71]. The inconsistent results may be accounted for by the finding that selective attention is more consistently found in depression when the stimuli are displayed for over half a second [e.g. 70, 72]. People with depression also exhibit difficulty in controlling their attention sufficiently to disengage from negative material. A range of studies have shown that people without depression attend away from negative stimuli and towards positive stimuli, whereas people with depression and people with elevated but nonclinical levels of depressed symptoms do not show this 'protective' bias [e.g. 73, 74].

In individuals diagnosed with an eating disorder, studies of attention have tended to group the different eating disorders together. Several studies have indicated that people with an eating disorder show increased emotional Stroop interference for both food and body-shaperelated words [75] and body shape pictures [76].

Taken together, depression, anxiety disorders and eating disorders affect attentional processes, narrowing attentional focus and biasing it toward disorder-congruent stimuli. This impairs the processing of other stimuli in the environment and constitutes a form of cognitive load that consumes attentional capacity and adversely affects speed of performance, performance on a secondary task, and problem solving [57, 77, 78]. Disruption of the secondary task extends to social interactions, since there is evidence that an elevated self-focus of attention impairs attention to details of the social situation, as indexed by poorer recall of partner information following an interaction $[79,80]$, although this finding is not always replicated [81]. Experimental studies indicate that attentional impairment in GAD [82] and depression [83] is more marked when there are competing stimuli in the environment.

\section{Maintenance of Preoccupation}

In addition to focusing attention on disorder-congruent negative stimuli, preoccupation has a self-perpetuating quality. This characteristic has been highlighted in the cognitive processes related both to anxiety and depression. Several laboratory studies have shown that chronic worriers are more likely to anticipate catastrophic outcomes than non-worriers, and this is associated with increased negative affect, which in turn leads to further catastrophising [84-86]. Parallel findings are evident from experimental manipulations of rumination that lead to the intensification and prolongation of depressed mood $[87,88]$. In turn, depressed mood increases the recall of negative information and negative inferences about events $[89,90]$. This issue has not been studied in the context of eating disorders, but the results from anxiety and depression research so far suggest that the persistence and recurrent nature of the negative thinking as- 
sociated with these disorders potentially further exacerbate the effects of this cognitive process.

Given this evidence concerning the self-perpetuating nature of preoccupation, and how preoccupation consumes cognitive capacity and attention in particular, the question is then raised as to how preoccupation might affect the mother's responsivity to her child.

\section{In What Ways Might Maternal Preoccupation Have an Impact on Infant Development?}

Taking the reviewed evidence together, recurrent negative thought, which we refer to as preoccupation, is characteristic of depression, anxiety and eating disorders, all of which commonly occur in the postnatal period. We argue that it is important to consider the potential impact of maternal preoccupation on infant development, because preoccupation results in reduced responsivity to the environment and is self-perpetuating. There is a growing body of evidence that infants, from the first few months of life, are sensitive to their carers' communications, and seek out certain forms of parental responsiveness [91-94]. In the section that follows, we review the considerable evidence that has accrued suggesting that different facets of parental responsivity influence key aspects of infant development.

\section{Maternal Sensitivity and Responsiveness}

Normal Samples. Numerous studies have shown that contingency of parental responsiveness plays a key role in infant development [95]. By 6 weeks, infants are clearly sensitive to the facial expressions and responses of their mothers and expect social contingency [93, 94, 96]. For example, in studies of normal samples using the still-face paradigm (where mothers are asked to show a blank unresponsive face to their infant) infants become increasingly distressed as their mothers remain apparently unmoved by their protests and attempts to interact [92]. Infants also learn to develop social anticipations and expectations about the behaviour of others [94], and prefer to attend to people who have been responsive to them in the past compared to those who have not [97].

Clinical Samples. Several studies have shown that postnatally depressed mothers have significant problems in showing sensitive responsiveness. Their children, in turn, show high distress levels and are more avoidant of contact [5, 98-100]. In two large UK community cohorts [101-103], postnatally depressed mothers were found to be less sensitive to their infants than control mothers.
The speech of depressed mothers to their infants was less focused on the infant's experience and included more criticism and hostility than the speech of healthy mothers [102]. Stein et al. [103] found that depressed mothers showed significantly less facilitation and rapport when interacting with their children than control mothers. Furthermore, depressed mothers and their children showed significantly less interaction in general than control mother-child pairs. Similarly, postnatal eating disorders have been found to be associated with a lack of maternal responsivity, which in turn is associated with adverse child outcome [10]. Having said that, Campbell et al. [3] studied low-risk first-time depressed mothers and found that while these mothers displayed lower level of positive engagement and affect than control mothers, there was no evidence of the negative, rejecting and intrusive type of interaction characteristic of some samples of high-risk mothers [e.g. 98]; thus, they suggest, rather than simply taking into account the depression status of the mother per se, 'more subtle aspects of parenting may be mediating any longer-term effects on the quality of the relationship or on infant outcome in relatively low-risk dyads'.

The evidence suggests that maternal insensitivity and lack of responsiveness in particular is critical. This conclusion is not a new one, but to date it has not been determined precisely what aspects of the maternal psychiatric state are responsible for this altered maternal responsivity. A number of researchers have pointed to cognitive processes involved in preoccupation as potentially responsible for the lack of maternal sensitivity. For example, Zahn-Waxler et al. [104] studied the impact of maternal depression on child development from ages 2-6 years. Although not measuring maternal preoccupation per se, they concluded that the caregiver's ability to take on the child's perspective (a child-centred orientation that encompasses the child's needs), is compromised by self-absorption and preoccupations, which are salient in depression. Sharp et al. [105] came to similar conclusions from their study of postnatal depression. Teti and Gelfand [106] also speculate that depression may affect cognitive processes by narrowing parents' attentional field and undermining their problem-solving abilities; thus, predisposing the individual to parenting deficits. Finally, in a detailed review of possible mechanisms, Goodman and Gotlib [107] proposed that exposure to negative maternal cognitions may result in the parent being an inadequate social partner for the child, as these cognitions prevent them from being responsive to the child's social and emotional needs. 
Empirical support for these processes comes, for example, from a study by Murray et al. [102], who found that, compared to controls, mothers with postnatal depression at 3 months were less infant-focused and more self-focused, and this was associated with adverse infant developmental outcome at 18 months. In eating disorders, it has been shown that the mother's focus on the infant's mess and self-feeding during mealtimes is associated with a diminished responsiveness to infant cues, ultimately leading to mother-infant conflict [108]. Field et al. [109] demonstrated that positive changes in maternal behaviour can be brought about experimentally. Mothers who had initially shown intrusive behaviours during interaction with their infants were asked to focus their thoughts on their infants for $5 \mathrm{~min}$. After the thought focus task, the mothers' intrusive behaviour decreased significantly. This might indicate potential intervention strategies.

These findings on mothers with depression, anxiety disorders and eating disorders, although tentative, suggest that recurrent negative thinking may be one of the factors contributing to the intergenerational transmission of disturbance. Moreover, it seems that by changing the focus of this thinking, it is possible to influence mother-child interaction, at least temporarily. Longitudinal studies would be needed to investigate whether this influence lasts.

\section{Impact on Infant Development}

Four important aspects of infant development have been shown to be impaired in the context of maternal insensitivity, particularly lack of contingency, and these are hypothesised to be affected by maternal preoccupation:

Infant Learning. One of the main functions of contingent responsiveness is to facilitate child learning. By observing their mother's responses to their cues, infants learn associations between stimuli and responses that teach them how to influence their carers' behaviour, as well as allowing instrumental learning $[110,111]$. Contingent parent-child interaction has been shown to predict infant persistence in mastery motivation tasks [112]. Ruddy and Bornstein [113] found that mothers who fostered their babies' attention to stimuli at 4 months of age had babies with larger speaking vocabularies at age 1 year. Furthermore, Papousek and Papousek [110] showed that when the parent's responses are not synchronised with the child's behaviour, learning is reduced [110], and subsequent performance in learning tasks is adversely affected [114].
Sustained Infant Attention. Contingent and appropriate behaviours by the parent are important for the development of sustained attention $[95,115-119]$. Sustained infant attention is necessary to allow a child to concentrate for long enough to process information, and hence is associated with learning $[118,120]$. Indeed, attentional measures in infancy have been found to be reliable predictors of IQ in later childhood [121]. Young children of mothers with depression have been found to show a less mature pattern of allocating their attention to objects than children of well mothers, since they attended to more objects than children of control mothers but for shorter time intervals [122]. This tendency of the children of depressed mothers was related to the number of times the mothers initiated and terminated the children's interaction with objects. Depressed mothers initiated and terminated their children's engagement with objects more frequently than well mothers did. High levels of attentional control in children have been found to be associated with low levels of negative emotionality [123-125], and high levels of attentional persistence at 15 months have been found to buffer the adverse effects of early emotional negativity on later social competence [126].

Joint Attention and Considering Other People as Intentional Agents. Towards the end of the first year of life there is a striking developmental change in mother-child interaction, and especially in the infant's attentional capacities. The infant becomes interested in the timing, direction and focus of the mother's attention [127, 128]. Infants begin to show an awareness of the focus of an adult caregiver's attention by following the direction of an adult's gaze or pointing $[127,129]$. This is known as 'joint attention'. One of the crucial tasks for a parent is to monitor the infant's focus of attention, responses, behaviour and mood in order for a mutual regulation of attention and affect to occur $[5,130]$. As one would expect, maternal sensitivity is crucial in this. The infant also monitors the adult's affective response to other people and objects, and regulates his/her behaviour on the basis of the adult's response, a process known as social referencing [131]. Empirical evidence of this comes, for example, from a recent study that shows that maternal sensitivity when the infant is 1 year of age predicts the infants propensity to engage with someone else in relation to the external world [132]. Both joint attention and social referencing encompass an important aspect of child development, that is the understanding of other people as intentional agents. This enables the development of other important skills, such as language acquisition [133]. For example, to facilitate object naming it is crucial that the child is able to deter- 
mine the adult's focus of attention on a particular object when hearing a new word referring to it. Otherwise it would be impossible for the child to associate words with their appropriate referents. Overall, therefore, the caregiver's responses to the external environment and her/his sensitivity to the child affect the child's behaviour and attention in important ways. As these are precisely the aspects of functioning that are affected by preoccupation, preoccupation could potentially have a significant impact on the child's development of joint attention and related skills.

Infant Emotional Regulation. Infants' capacities to regulate their internal state, behaviour and emotions are key developmental tasks which have considerable influence on infants' subsequent development. One of the key roles that parental support plays is to enable the child to develop greater tolerance for higher arousal states [134]. Parents regulate infant arousal by carefully monitoring the infant state and then using soothing and calming responses [118]. Attentional control and persistence are important ingredients in emotional regulation [116, 126, 130, 135]. The work of Tronick [136] on the mother's facilitation of mother-child interaction from asynchrony to synchrony indicates the key role that a mother's attention to her infant plays in emotional regulation. Such parental behaviour promotes early self-regulation and influences later adjustment $[117,137]$. Elsewhere, we have proposed [138] that the impact on the infant may extend to elements of the controllability over emotional responding (in other words, learning emotional regulation) and predictability (in that a response elicits an outcome from the caregiver), both of which are considered central to emotional stability [e.g. 139].

\section{Summary}

The research reviewed above converges on the conclusion that core areas of infant development are dependent on maternal attention and responsiveness. Our proposal is that preoccupation is one of the key factors that compromise maternal responsiveness and thereby it adversely affects child outcome.

It is important to note that identifying preoccupation as one of the key factors affecting maternal responsiveness does not mean that we have identified a particular behavioural marker that is characteristic to all preoccupied mothers. Anxious mothers are likely to be preoccupied by threats in the environment and behave in an overprotective manner towards their infants, potentially leading to intrusive behaviour. In contrast, depressed mothers are likely to be preoccupied by their thoughts of failure and low self-esteem, which may manifest in withdrawn behaviour. This has implications in terms of intervention, as discussed below. Finally, it is worth mentioning that all mothers do at times get preoccupied by things and do display these types of behaviour. Therefore, preoccupation per se is not exclusive to mothers with psychiatric disorders. However, mothers who are not experiencing psychiatric disorders are much more likely to be able to control their preoccupation. This sets them apart from mothers with psychiatric disorders, as they are unlikely to be preoccupied for prolonged time periods when interacting with their children.

\section{Future Research}

The research to date suggests that adverse child outcomes are associated with maternal psychiatric disorder, and provides indirect support for the proposal that preoccupation is one of the mechanisms in the intergenerational transmission of psychiatric disturbance. The possibility that preoccupation is one of the cognitive processes involved raises several directions of enquiry for future research. In this paper, we have concentrated on the role of the mother, because to date this is where most of the research has focused. The likelihood that the level of preoccupation of fathers and other caregivers may exacerbate or moderate the proposed relationship between maternal preoccupation and child development requires empirical attention.

If the role of maternal preoccupation is supported by empirical research, this will provide an important avenue for the development of effective treatments to prevent transmission of disturbance. There would be two potential targets for treatment. The first important focus would be to treat the mother's preoccupation. A likely first step in developing such treatments would be to adapt interventions from the treatment of rumination in depression and the treatment of worry in GAD. The second approach would concentrate specifically on the mother-child interaction by guiding mothers to respond sensitively to their infants by helping them to focus their attention on their infant's signals, communication and behaviour rather than on their own thoughts and worries. One possible method for this would be video feedback, which has been used successfully to enhance maternal sensitivity in other situations, such as following adoption [140]. The challenge here is, of course, the diverse behaviour that can be characteristic for preoccupied mothers, and consequently a wide variety of interventions is likely to be required. 


\section{Conclusion}

Although previous research has identified particular parenting behaviours and responses that are linked to adverse child outcome, the cognitive features of maternal psychopathology which underlie this non-optimal parenting remain to be identified. The key question is why mothers have difficulties in detecting and acknowledging infant signals. We argue that one of the important unexplored factors is parental preoccupation. We hypothesise that preoccupation acts as a proximal step in the transmission of disturbance, in that it interferes with the parents' capacity to attend to their infants and provide responsive interactions. Notwithstanding that certain features of maternal disturbance are disorder specific $[9,141]$, we hypothesise that the key feature of maternal disturbance across disorders is preoccupation, and that it is this preoccupation which disrupts the attentional processes necessary for parental responsiveness. Future research in this area is important for two reasons. Scientifically, it will test an important potential mechanism by which maternal psychiatric disorder interferes with infant development. Clinically, if preoccupation is found to be one of the crucial mechanisms, this will provide specific information for the development of clinical interventions.

\section{Acknowledgements}

This research was supported by the Wellcome Trust, UK. We would like to gratefully acknowledge the contributions of Helen Woolley, Lynne Murray, Christopher Fairburn, Sandra Cooper, Peter Cooper, Rebecca Park, Silvie Hepburn, Georgina Krebs and Heather Williams.

\section{References}

-1 Merikangas KR, Dierker LC, Szatmari P: Psychopathology among offspring of parents with substance abuse and/or anxiety disorders: a high risk study. J Child Psychol Psychiatry 1998;39:711-720.

2 Barnes J, Stein A: Effects of parental psychiatric illness on child development; in Gelder MG, Lopez-Ibor JJ, Andreason NC (eds): New Oxford Textbook of Psychiatry. Oxford, Oxford University Press, 2000.

-3 Campbell SB, Cohn JF, Meyers T: Depression in first-time mothers: mother-infant interaction and depression chronicity. Dev Psychol 1995;31:349-357.

4 Cohn JF, Campbell SB: Influence of maternal depression on infant affect regulation; in Cicchetti D, Toth S (eds): Developmental Perspectives on Depression. Rochester, University of Rochester Press, 1992, pp 103130.

5 Field TM: Infants of depressed mothers. Infant Behav Dev 1995;18:1-13.

-6 Hay DF, Pawlby S, Sharp D, Asten P, Mills A, Kumar R: Intellectual problems shown by 11-year-old children whose mothers had postnatal depression. J Child Psychol Psychiatry 2001;42:871-889.

7 Murray L, Cooper P: Intergenerational transmission of affective and cognitive processes associated with depression: infancy and the preschool years; in Goodyer I (ed): Unipolar Depression: A Lifespan Perspective. Oxford, Oxford University Press, 2003, pp 17-46.

8 Jacobi C, Agras WS, Hammer L: Predicting children's reported eating disturbances at 8 years of age. J Am Acad Child Adolesc Psychiatry 2001;40:364-372.
Patel P, Wheatcroft R, Park RJ, Stein A: The children of mothers with eating disorders. Clin Child Fam Psychol Rev 2002;5:1-19.

10 Stein A, Woolley H, Cooper SD, Fairburn CG: An observational study of mothers with eating disorders and their infants. J Child Psychol Psychiatry 1994;35:733-748.

11 Stice E, Agras WS, Hammer LD: Risk factors for the emergence of childhood eating disturbances: a five-year prospective study. Int J Eat Disord 1999;25:375-387.

12 Murray L, Cooper P, Creswell C, Schofield E, Sack C: The effects of maternal social phobia on mother-infant interactions and infant social responsiveness. J Child Psychol Psychiatry 2007;48:45-52.

13 Rutter M: Psychiatric disorder in parents as a risk factor for children; in Shaffer D, Phillips I, Enger NB (eds): Prevention of Mental Disorders, Alcohol and other Drug use in Children and Adolescents. Rockville, Office for Substance Abuse, United States Department of Health and Human Services, 1989, pp 157-189.

14 Fonagy P, Steele H, Steele M: Maternal representations of attachment during pregnancy predict the organization of infant-mother attachment at one year of age. Child Dev 1991;62:891-905.

15 Tronick EZ: Emotions and emotional communication in infants. Am Psychol 1989;44: 112-119.

16 Cicchetti D, Rogosch F, Toth S: Maternal depressive disorder and contextual risk: contributions to the development of attachment insecurity and behavior problems in toddlerhood. Dev Psychopathol 1998;10:283300 .
17 Plomin R, DeFries JC, Craig IW, McGuffin P: Behavioral Genetics in the Postgenomic Era. Washington, American Psychological Association, 2003.

18 Fonagy P, Steele M, Steele H, Moran, GS, Higgitt AC: The capacity for understanding mental states: the reflective self in parent and child and its significance for security of attachment. Infant Ment Health J 1991;12:201218.

19 McGrath M, Zachariah BCF, Lester BM: Determinants of maternal self-esteem in the neonatal period. Infant Ment Health J 1993; 14:35-48.

20 Stern D: The Interpersonal World of the Infant. London, Karnac Books, 1998.

21 Feshbach ND: Empathy and physical abuse; in Cicchetti D, Carlson V (eds): Child Maltreatment: Theory and Research on the Causes and Consequences of Child Abuse and Neglect. Cambridge, Cambridge University Press, 1989, pp 349-376.

22 Oxford English Dictionary (electronic version), ed 2. Oxford, Oxford University Press, 2007.

23 Primary maternal preoccupation: in Winnicott DW (ed): Collected Papers - Through Paediatrics to Psychoanalysis. London, Tavistock Publications, 1958

24 Leckman JF, Mayes LC, Feldman R, Evans DW, King RA, Cohen DJ: Early parental preoccupations and behaviors and their possible relationship to the symptoms of obsessivecompulsive disorder. Acta Psych Scan Suppl 1999;396:1-26. 
25 Hesse E: The Adult Attachment Interview: historical and current perspectives; in Cassidy J, Shaver PR (eds): Handbook of Attachment: Theory, Research, and Clinical Applications. New York, Guilford Press, p xvii 925.

-26 Cooper P, Murray L: Prediction, detection, and treatment of postnatal depression. Arch Dis Child 1997;77:97-99.

-27 Kessler RC, DuPont RL, Berglund P, Wittchen HU: Impairment in pure and comorbid generalized anxiety disorder and major depression at 12 months in two national surveys. Am J Psychiatry 1999;156:1915-1923.

-28 Wittchen HU, Zhao S, Kessler RC, Eaton WW: DSM-III-R generalized anxiety disorder in the National Comorbidity Survey. Arch Gen Psychiatry 1994;51:355-364.

-29 Kessler RC, Keller MB, Wittchen HU: The epidemiology of generalized anxiety disorder. Psychiatr Clin North Am 2001;24:1939.

-30 Matthey S, Barnett B, Howie P, Kavanagh D: Diagnosing postpartum depression in mothers and fathers: whatever happened to anxiety? J Affect Disord 2003;74:139-147.

>31 Wenzel A, Haugen E, Jackson L, Brendle J: Anxiety symptoms and disorders at eight weeks postpartum. J Anxiety Disord 2005; 19:295-311.

$\$ 32$ Hoek HW: Review of the epidemiological studies of eating disorders. Int Rev Psychiatry 1993;5:61-74.

33 Harvey AG, Watkins E, Mansell W, Shafran R: Cognitive Behavioural Processes across Psychological Disorders: A Transdiagnostic Approach to Research and Treatment. Oxford, Oxford University Press, 2004.

34 Borkovec TD, Robinson E, Puzinsky T, DePree JA: Preliminary exploration of worry: some characteristics and processes. Behav Res Ther 1983;21:9-16.

>35 Nolen-Hoeksema S: The role of rumination in depressive disorders and mixed anxiety/ depressive symptoms. J Abnorm Psychol 2000;109:504-511.

-36 Nolen-Hoeksema S: Responses to depression and their effects on the duration of depressive episodes. J Abnorm Psychol 1991;100: 569-582.

$\checkmark 37$ Troop NA, Treasure JL: Psychosocial factors in the onset of eating disorders: responses to life-events and difficulties. Br J Med Psychol 1997;70:373-385.

-38 Fresco DM, Frankel AN, Mennin DS, Turk CL, Heimberg RG: Distinct and overlapping features of rumination and worry: the relationship of cognitive production to negative affective states. Cognit Ther Res 2002;26: 179-188.

-39 Harrington JA, Blankenship V: Ruminative thoughts and their relation to depression and anxiety. J Appl Soc Psychol 2002;32:465485.
40 Segerstrom SC, Tsao JCI, Alden LE, Craske MG: Worry and rumination: repetitive thought as a concomitant and predictor of negative mood. Cognit Ther Res 2000;24: 671-688.

41 Szabo M, Lovibond PF: The cognitive content of naturally occurring worry episodes. Cognit Ther Res 2002;26:167-177.

42 Klinger E: Emotional influences on cognitive processing, with implications for theories of both; in Gollwitzer PM, Bargh JA (eds): The Psychology of Action: Linking Cognition and Motivation to Behaviour. New York, Guilford Press, 1996, pp 168189.

43 Craske MG, Hazlett-Stevens H: Facilitating symptom reduction and behavior change in GAD: the issue of control. Clin Psychol Sci Pract 2002;9:69-75.

44 Craske MG, Rapee RM, Jackel L, Barlow DH: Qualitative dimensions of worry in DSMIII-R generalized anxiety disorder subjects and non-anxious controls. Behav Res Ther 1989;27:397-402.

45 Roemer L, Borkovec TD: Worry: unwanted cognitive activity that controls unwanted somatic experience; in Wegner DM, Pennebaker JW (eds): Handbook of Mental Control. Englewood Cliffs, Prentice Hall, 1993, pp 220-238.

46 Cooper PJ, Cooper Z, Hill C: Behavioral treatment of bulimia nervosa. Int J Eat Disord 1989;8:87-92.

47 Rosen JC, Reiter J, Orosan P: Assessment of body image in eating disorders with the Body Dysmorphic Disorder Examination. Behav Res Ther 1995;33:77-84.

48 Nolen-Hoeksema S, Morrow J: Effects of rumination and distraction on naturally occurring depressed mood. Cogn Emot 1991;7: 561-570.

49 Exner JE: The Self-Focus Sentence Completion: a study of egocentricity. J Pers Assess 1973;37:437-455.

50 McIntosh WD, Martin LL: The cybernetics of happiness: the relation of goal attainment, rumination, and affect. Pers Soc Psychol Rev 1992;14:222-246.

51 Meyer TJ, Miller ML, Metzger RL, Borkovec TD: Development and validation of the Penn State Worry Questionnaire. Behav Res Ther 1990;28:487-495.

52 Lyubomirsky S, Kasri F, Zehm K: Dysphoric rumination impairs concentration on academic tasks. Cognit Ther Res 2003;27:309_ 330.

53 Wentzlaff R, Rude S, Taylor C, Stultz C Sweatt R: Beneath the veil of thought suppression: attentional bias and depression risk. Cogn Emot 2001;15:435-452.

54 Ingram RE: Self-focused attention in clinica disorders: review and a conceptual model. Psychol Bull 1990;107:156-176.

55 Mor N, Winquist J: Self-focused attention and negative affect: a meta-analysis. Psychol Bull 2002;128:638-662.
56 Williams JMG, Watts FN, MacLeod C, Mathews A: Cognitive psychology and emotional disorders. Oxford, Wiley, 1988.

57 Williams JMG, Watts FN, MacLeod C, Mathews A: Cognitive psychology and emotional disorders. Chichester, Wiley, 1997.

58 Ehlers A: Cardiac perception, panic attacks, and phobias; in Vaitl D, Schandry R (eds): From the Heart to the Brain: The Psychophysiology of Circulation - Brain Interaction. New York, Peter Lang, 1995, pp 299313.

59 Clark D, Wells A: Cognitive therapy for anxiety disorders; in Dickstein L, Riba M, Oldham J (eds): American Psychiatric Press Review of Psychiatry. Washington, American Psychiatric Association, 1997, vol 16, pp I9-I-43.

60 Ben-Tovim DI, Walker MK, Fok D, Yap E: An adaptation of the Stroop Test for measuring shape and food concerns in eating disorders: a quantitative measure of psychopathology? Int J Eat Disord 1989;8:681-687.

61 Cooper MJ, Fairburn CG: Demographic and clinical correlates of selective information processing in patients with bulimia nervosa. Int J Eat Disord 1993;13:109-116.

62 Jones-Chesters MH, Monsell S, Cooper PJ: The disorder-salient Stroop effect as a measure of psychopathology in eating disorders. Int J Eat Disord 1998;24:65-82.

63 Schotte DE, McNally RJ, Turner ML: A dichotic listening analysis of body weight concern in bulimia nervosa. Int J Eat Disord 1990;9:109-113.

64 Fairburn CG, Shafran R, Cooper Z: A cognitive behavioural theory of anorexia nervosa. Behav Res Ther 1999;37:1-13.

65 Kahneman D: Attention and Effort. Englewood Cliffs, Prentice Hall, 1973

66 Foa EB, McNally RJ: Sensitivity to feared stimuli in obsessive-compulsives: a dichotic listening analysis. Cognit Ther Res 1986;10: 477-485.

67 Mathews A, MacLeod C: Selective processing of threat cues in anxiety states. Behav Res Ther 1985;23:563-569.

68 Chen E, Lewin MR, Craske MG: Effects of state anxiety on selective processing of threatening information. Cognit Emot 1996; 10:225-240.

69 Bradley BP, Mogg K, Millar N, White J: Selective processing of negative information: effects of clinical anxiety, concurrent depression, and awareness. J Abnorm Psychol 1995; 104:532-536.

70 Gotlib IH, Cane DB: Construct accessibility and clinical depression: a longitudinal investigation. J Abnorm Psychol 1987;96:199204.

71 Mogg K, Bradley BP, Williams R, Mathews A: Subliminal processing of emotional information in anxiety and depression. J Abnorm Psychol 1993;102:304-311. 
72 Mogg K, Bradley BP, Williams R: Attentional bias in anxiety and depression: the role of awareness. Br J Clin Psychol 1995;34:17-36.

73 Gotlib IH, McLachlan AL, Katz AN: Biases in visual attention in depressed and nondepressed individuals. Cogn Emot 1988;2:185200

74 McCabe SB, Gotlib IH: Selective attention and clinical depression: performance on a deployment of attention task. J Abnorm Psychol 1995;104:241-245

-75 Sackville T, Schotte DE, Touyz SW, Griffiths $\mathrm{R}$, Beumont PJV: Conscious and preconscious processing of food, body weight and shape, and emotion-related words in women with anorexia nervosa. Int J Eat Disord 1998; 23:77-82.

-76 Walker MK, Ben-Tovim DI, Paddick S, McNamara J: Pictorial adaptation of Stroop measures of body-related concerns in eating disorders. Int J Eat Disord 1995;17:309-311.

77 Eysenck MW, Calvo MG: Anxiety and performance: the processing efficiency theory. Cogn Emot 1992;6:409-434.

78 Sarason IG, Sarason BR, Keefe DE, Hayes $\mathrm{BE}$, Shearin EN: Cognitive interference: situational determinants and trait-like characteristics. J Pers Soc Psychol 1986;51:215226.

79 Hope D, Heimberg R, Klein J: Social anxiety and the recall of interpersonal information. J Cognit Psychother 1990;4:185-195.

$>80$ Daly JA, Vangelisti AL, Lawrence SG: Selffocused attention and public speaking anxiety. Pers Individ Dif 1990;10:903-913.

-81 Stopa L, Clark D: Cognitive processes in social phobia. Behav Res Ther 1993;31:255267.

82 Mogg K, Mathews A, Eysenck M, May J: Biased cognitive operations in anxiety: artefact, processing priorities or attentional search? Behav Res Ther 1991;29:459-467.

$>83$ Rokke PD, Arnell KM, Koch MD, Andrews JT: Dual-task attention deficits in dysphoric mood. J Abnorm Psychol 2002;111:370-379.

84 Harvey AG, Greennall E: Catastrophic worry in primary insomnia. J Behav Ther Exp Psychiatry 2003;34:11-23.

85 Startup HM, Davey GCL: Mood as input and catastrophic worrying. J Abnorm Psychol 2001;110:83-96.

-86 Vasey MW, Borkovec TD: A catastrophizing assessment of worrisome thoughts. Cogn Ther Res 1992;16:505-520.

$>87$ Morrow J, Nolen-Hoeksema S: Effects of responses to depression on the remediation of depressive affect. J Pers Soc Psychol 1990;58: 519-527.

-88 Nolen-Hoeksema S, Morrow J: A prospective study of depression and posttraumatic stress symptoms after a natural disaster: the 1989 Loma Prieta earthquake. J Pers Soc Psychol 1991;61:115-121.

89 Blaney PH: Affect and memory: a review. Psychol Bull 1986;99:229-246.
-90 Teasdale JD: Psychological treatments for depression: how do they work? Behav Res Ther 1985;23:157-165.

91 Lewis M, Goldberg S: Perceptual-cognitive development in infancy: a generalized expectancy model as a function of the mother-infant interaction. Merrill Palmer Q 1969; 15:81-100.

92 Murray L, Trevarthen C: Emotional regulation of interactions between two-montholds and their mothers; in Field TM, Fox NA (eds): Social Perception in Infants. Norwood, Ablex, 1985, pp 177-197.

$\checkmark 93$ Nadel J, Carchon I, Kervella C, Marcelli D, Reserbat-Plantey D: Expectancies for social contingency in 2-month-olds. Dev Sci 1999; 2:164-173.

94 Rochat P, Striano T: Social-cognitive development in the first year, in Rochat P (ed) Early Social Cognition: Understanding Others in the First Months of Life. Mahwah, Lawrence Erlbaum, 1999, p ix 341.

95 Papousek H, Papousek M: Intuitive parenting: a dialectic counterpart to the infant's integrative competence; in Osofsky JD (ed): Handbook of Infant Development. New York, Wiley, 1987, pp 669-720.

96 De Haan M, Nelson CA: Discrimination and categorisation of facial expressions of emotion during infancy; in Slater A (ed) Perceptual Development: Visual, Auditory, and Speech Perception in Infancy. Hove, Psychology Press, 1998, pp 287-309.

97 Bigelow AE, Birch SAJ: The effects of contingency in previous interactions on infants' preference for social partners. Infant Behav Dev 1999;22:367-382.

98 Cohn JF, Matias R, Tronick EZ, Connell D, Lyons-Ruth D: Face-to-face interactions of depressed mothers and their infants; in Tronick EZ, Field T (eds): Maternal Depression and Infant Disturbance: New Directions for Child Development. San Francisco, Jossey-Bass, 1986, pp 31-46.

99 Field TM: Early interactions between infants and their postpartum depressed mothers. Infant Behav Dev 1984;7:517522.

100 Field T, Healy B, Goldstein S, Perry S, Bendell D, Schanberg S, Zimmerman EA, Kuhn $\mathrm{C}$ : Infants of depressed mothers show 'depressed' behavior even with non-depressed adults. Child Dev 1988;59:1569-1579.

101 Murray L, Fiori-Cowley A, Hooper R, Cooper P: The impact of postnatal depression and associated adversity on early motherinfant interactions and later infant outcomes. Child Dev 1996;67:2512-2526.

102 Murray L, Kempton C, Woolgar M, Hooper R: Depressed mothers' speech to their infants and its relation to infant gender and cognitive development. J Child Psychol Psychiatry 1993;34:1083-1101.

103 Stein A, Gath DH, Bucher J, Bond A, Day A Cooper PJ: The relationship between postnatal depression and mother-child interaction. Br J Psychiatry 1991;158:46-52.
104 Zahn-Waxler C, Iannotti RJ, Cummings EM, Denham S: Antecedents of problem behaviors in children of depressed mothers. Dev Psychopathol 1990;2:271-291.

105 Sharp D, Hay DF, Pawlby S, Schmuecker G, Allen H, Kumar R: The impact of postnatal depression on boys' intellectual development. J Child Psychol Psychiatry 1995;36: 1315-1336.

106 Teti DM, Gelfand DM: Maternal cognitions as mediators of child outcomes in the context of postpartum depression; in Murray L, Cooper PJ (eds): Postpartum Depression and Child Development. New York, Guilford Press, 1997, pp 136-164.

107 Goodman SH, Gotlib IH: Risk for psychopathology in the children of depressed mothers: a developmental model for understanding mechanisms of transmission. Psychol Rev 1999;106:458-490.

108 Stein A, Woolley H, McPherson K: Conflict between mothers with eating disorders and their infants during mealtimes. Br J Psychiatry 1999; 175:455-461.

109 Hart S, Field T, Jones N, Yando R: Intrusive and withdrawn behaviours of mothers interacting with their infants and boyfriends. J Child Psychol Psychiatry 1999;40:239245.

110 Papousek H, Papousek M: Fragile aspects of early social integration; in Murray L, Cooper P (eds): Postpartum Depression and Child Development. New York, Guilford Press, 1997, pp 35-53.

111 Stanley C, Murray L, Stein A: The effect of postnatal depression on mother-infant interaction, infant response to the still-face perturbation and performance on an instrumental learning task. Dev Psychopathol 2004;16:1-18.

112 Yarrow LJ, MacTurk RH, Vietze PM, McCarthy ME, Klein RP, McQuiston S: Development course of parental stimulation and its relationship to mastery motivation during infancy. Dev Psychol 1984;20:492-503.

113 Ruddy MG, Bornstein MH: Cognitive correlates of infant attention and maternal stimulation over the first year of life. Child Dev 1982;53:183-188.

114 Dunham P, Dunham F: Effects of motherinfant social interactions on infants' subsequent contingency task performance. Child Dev 1990;61:785-793.

115 Belsky J, Goode MK, Most RK: Maternal stimulation and infant exploration: crosssectional, correlational and experimental analyses. Child Dev 1980;51:1168-1178.

116 Brazelton TB, Koslowski B, Main M: The origins of reciprocity: the early mother-infant interaction; in Lewis $M$, Rosenblum LA (eds): The Effect of the Infant on its Caregiver. New York, Wiley, 1974.

$\checkmark 117$ Jaffe J, Beebe B, Feldstein S, Crown CL, Jasnow MD: Rhythms of dialogue in infancy: coordinated timing in development. Monogr Soc Res Child Dev 2001;66:i-vii, $1-132$. 
118 Ruff HA, Rothbart MK: Attention in early development: themes and variations. New York, Oxford University Press, 1996.

119 Stern DN, Beebe B, Jaffe J, Bennett S: The infant's stimulus world during social interaction: a study of caregiver behaviour with particular reference to repetition and timing; in Schaffer HR (ed): Studies in MotherInfant Interaction. London, Academic Press, 1977.

120 Lawson KR, Ruff HA: Focused attention: assessing a fundamental cognitive process in infancy; in Singer LT, Sanford P (eds): Biobehavioral Assessment of the Infant. New York, Guilford Press, 2001, pp 293311.

-121 Slater A: Individual differences in infancy and later IQ. J Child Psychol Psychiatry 1995;36:69-112.

122 Breznitz Z, Friedman SL: Toddler's concentration: does maternal depression make a difference? J Child Psychol Psychiatry 1988; 29:267-279.

- 123 Kochanska G, Coy KC, Tjebkes TL, Husarek SJ: Individual differences in emotionality in infancy. Child Dev 1998;69:375390.

124 Kochanska G, Murray KT, Harlan ET: Effortful control in early childhood: continuity and change, antecedents, and implications for social development. Dev Psychol 2000;36:220-232.

125 Rothbart MK, Ziaie H, O’Boyle CG: Selfregulation and emotion in infancy; in Eisenberg N, Fabes RA (eds): Emotion and its Regulation in Early Development: New Directions for Child Development. San Francisco, Jossey-Bass, 1992, vol 55, pp 723.
126 Belsky J, Friedman SL, Hsieh KH: Testing a core emotion-regulation prediction: does early attentional persistence moderate the effect of infant negative emotionality on later development? Child Dev 2001;72:123133

127 Butterworth G: The ontogeny and phylogeny of joint visual attention; in Whiten A (ed): Natural Theories of Mind: Evolution, Development and Simulation of Everyday Mind-Reading. Oxford, Blackwell, 1991, p xiv 362.

128 Moore C, Corkum V: Social understanding at the end of the first year of life. Dev Rev 1994;14:349-372.

129 Trevarthen C, Hubley P: Secondary intersubjectivity: confidence, confiding and acts of meaning in the first year; in Lock A (ed) Action, Gesture, and Symbol: The Emergence of Language. London, Academic Press, 1978, pp 183-229.

130 Reddy V, Hay D, Murray L, Trevarthen C: Communication in infancy: mutual regulation of affect and attention; in Bremner G, Slater A, Butterworth G (eds): Infant Development: Recent Advances. Hove, Psychology Press, 1997.

131 Feinman S, Roberts D, Hsieh K-F, Sawyer D, Swanson D: A critical review of social referencing in infancy, in Feinman S (ed): Social Referencing and The Social Construction of Reality in Infancy. New York, Plenum, 1992.

132 Hobson PR, Patrick MPH, Crandell LE Garcia-Perez RM, Lee A: Maternal sensitivity and infant triadic communication. J Child Psychol Psychiatry 2004;45:470480.
133 Tomasello M: Joint attention as social cognition; in Moore C, Dunham P (eds): Joint Attention: Its Origins and Role in Development. Hillsdale, England, Lawrence Erlbaum Associates, 1995, pp 103-130.

134 Roggman LA: Assessing social interactions of mothers and infants through play; in Schaefer CE, Gitlin K, Sandgrund A (eds): Play Diagnosis and Assessment. New York, Wiley, 1991, pp 427-462.

135 Stern DN: The Interpersonal World of the Infant: A View from Psychoanalysis and Developmental Psychology. New York, Basic Books, 1985.

136 Tronick EZ: Emotions and emotional communication in infants. Am Psychol 1989; 44:112-119.

137 Isabella RA, Belsky J: Interactional synchrony and the origins of infant-mother attachment: a replication study. Child Dev 1991;62:373-384.

138 Craske MG: The origins of phobias and anxiety disorders: why more women than men. Oxford, Elsevier Science, 2003.

139 Barlow DH: Anxiety and its disorders: the nature and treatment of anxiety and panic. New York, Guilford Press, 1988.

140 Juffer F, Hoksbergen RAC, Riksen-Walraven JM, Kohnstamm GA: Early intervention in adoptive families: supporting maternal sensitive responsiveness, infantmother attachment, and infant competence. J Child Psychol Psychiatry 1997;38: 1039-1050.

141 Murray L, Cooper PJ: Postpartum depression and child development. New York, Guilford Press, 1997. 